\title{
19
}

\section{Benchmarking of Bid Preparation for Capital Goods}

\author{
B. HIRSCH, M. KRÖMKER, K.-D. THOBEN, A. WICKNER \\ BIBA (Bremen Institute of Industrial Technology and Applied Work Science) \\ Hochschulring 20, D-28359 Bremen, E-mail: kro@biba.uni-bremen.de
}

\begin{abstract}
This paper describes an application example (case study) for the use of benchmarking strategies. The ESPRIT project 7131 focusses on the overall improvement of the bid preparation process. Three multinational companies representing industries with products engineered-to-order benchmarked their bid preparation process against each other.

The method used for enterprise modelling was IDEF0, a technique based on the SADT approach (hierarchical decomposing of processes). Applying this technology, the "as-is" situation was captured and analyzed. Both bottlenecks as well as best practices were determined. A generally applicable "to-be" situation was defined and implemented.
\end{abstract}

Keywords: Benchmarking, Bid Preparation, Enterprise Modelling, IDEF0, Software Design.

\section{INTRODUCTION}

Every day companies producing capital goods ${ }^{1}$ face a serious dilemma - a potentially interesting request is presented, but to be successful a convincing, attractive, and reliable bid $^{2}$ must be prepared - and this causes costs in terms of time as well as other resources. The task may become enormously complex when all EC member countries are fused into one "home market" and - in a broader perspective - when international competition turns into a global encounter. Especially small and medium-sized companies will face difficulties in their attempts to exploit the market potential. Companies must undergo tremendous change if they are to survive, grow, and prosper in this environment.

Figure 1 gives an overview of the bid-related activities. Beginning with the reception of an inquiry, a technical concept meeting customer demands must be developed. Next, the costs for realisation have to be calculated and a realistic delivery date has to be estimated. Commercial conditions including the salesprice, transport, warranty, etc. have to be fixed. Finally, all relevant information is compiled into a document - the bid - which is submitted to

${ }^{1}$ Typical examples for capital goods are machines, robots or assembly lines - goods, companies have to invest in in order to facilitate production.

${ }^{2}$ Synonyms, and possibly more common expressions for the word bid, are offer, quotation or tender. 
the customer. In case an order is placed (dotted line), the information generated has to be transferred to the relevant departments executing the order.

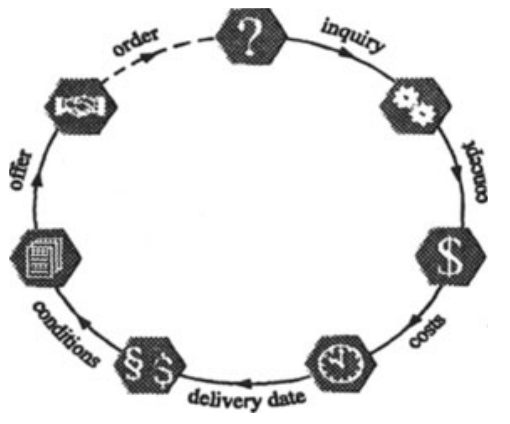

Fig. 1 The Bid Preparation Process

The situation in the capital goods industry can be described as a "competitive arena". Bids, based on poor or incomplete information, have to be prepared under high time pressure due to tight deadlines set by the potential customer. The concept developed within the bid often has to undergo "last minute modifications" - the customer changes his mind quickly. Generally, costs effected by bid preparation are not reimbursed directly but covered by the realized orders. Therefore, resources have to be minimized. The capital goods industry is characterized by strong competition. As a result, the winning chances are low (on an average $10 \%$ or less).

The Commission of the European Communities (CEC) is backing a project entitled "An Integrated System for Simultaneous Bid Preparation" (BIDPREP) which aims at developing a computerized system capable of supporting the bid preparation process by applying the concurrent engineering concept. The BIDPREP project runs from July 1992 to June 1995 and the human resource investment will total 23 man-years. The project is funded by the CEC under the ESPRIT programme (Project No. 7131) as well as by participating partners from Norway, Denmark, Italy and Germany.

One major focus of the BIDPREP project is the implementation and use of benchmarking strategies for developing a general applicable methodology for the bid preparation phase and creating new paths of supporting this process by software tools. In this context, benchmarking was understood as the process of identifying the best methods and practices and adopting or adapting the good features and implementing them to improve business processes.

\section{THE INITIAL SITUATION}

Within BIDPREP, three multinational companies, $\mathrm{ABB}$, Krüger Engineering and Guehring Automation, formed a consortium together with three research institutes and a software developer in order to develop both an efficient methodology as well as a computer-based system supporting the preparation of bids.

Significant is the fact that - although the ABB subdivision in Strommen, Norway, produces rolling stock for railways; Krüger Engineering, Copenhagen, is engaged in environmental protection; and Guehring Automation in Frohnstetten, Germany, manufactures grinding machines - the anticipated bottlenecks are similar and thereby independent of the product. The strategy for optimizing the process is to analyze the state-of-the-art proceeding, identifying bottlenecks as well as proven methods and thereby forming a generalized methodology which will be implemented in the final phase. 


\section{ANALYSIS OF THE “AS-IS" SITUATIONS}

In order to compare the work flow of bid preparation at the users' sites, an appropriate modelling technique had to be agreed upon. The consortium decided on IDEF0, a technique that is based on the SADT approach. IDEF0 [2] allows the hierarchical decomposing of business processes down to the required level of detailing. It identifies activities, related in- and outputs as well as steering information, so-called controls. Moreover, mechanisms to support the activities can be identified. Figure 2 displays the graphical method.

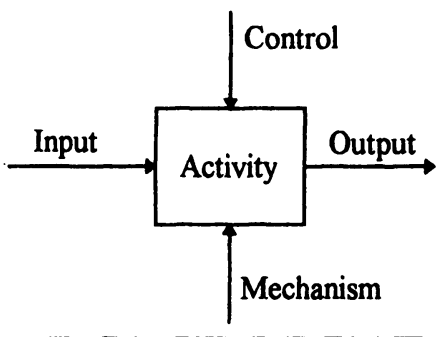

Fig. 2: The IDEF0 Method

As a first step, IDEF0 models for each company's bid preparation process were prepared. Figures 3 and 4 show how the preparation of bids is performed at Krüger Engineering and Guehring Automation. The analyses describe the "as-is" situations.

\subsection{Bid Preparation at Krïger Engineering}

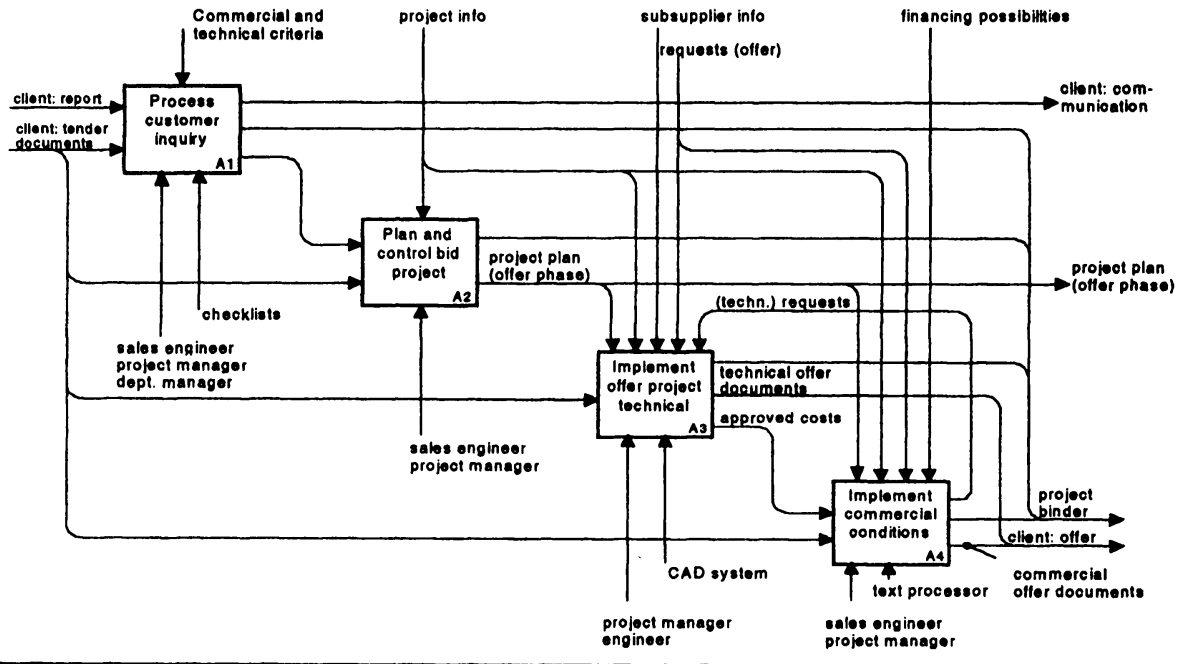

Fig. 3 Bid Preparation at Krüger Engineering

Krüger Engineering, a company within the Krüger Group, engages in activities of environmental protection, wastewater treatment, and energy supply in more than 30 countries worldwide. The bid preparation for a plant is handled as a project, managed by a project manager for the technical aspects and a sales engineer for the commercial aspects. The analysis revealed that the bid preparation is a very complex task involving various process, civil, mechanical, electrical and control engineers. Furthermore, an effective reuse of former information generated is very important. The reuse, however, is limited by the knowledge and experience of the individual employees. Currently, the process is supported by some PCbased applications (i.e. a text processor and a CAD system). 
A major objective of Krüger Engineering is to increase the cooperation and teamwork through simultaneous and transparent access to the needed and relevant information during the preparation of an offer. Actually, no support for their subsidiaries is given. Best practices identified at Krüger's sites are the overall management of the bid preparation process including periodical meetings for all employees involved as well as well-defined checklists allowing risk analysis and an evaluation of all incoming inquiries.

\subsection{Bid Preparation at Guehring Automation}

Guehring Automation designs and produces high-speed grinding machine tools. The analysis (see Figure 4) shows that many decisions have to be discussed internally, justified, approved and communicated during the bid preparation phase. The number of employees involved depends on the complexity of the machine tool requested, i.e. whether an existing concept, a partly new concept, or a completely new concept has to be applied. The process is performed manually, supported by both an administrative and an MRP system.

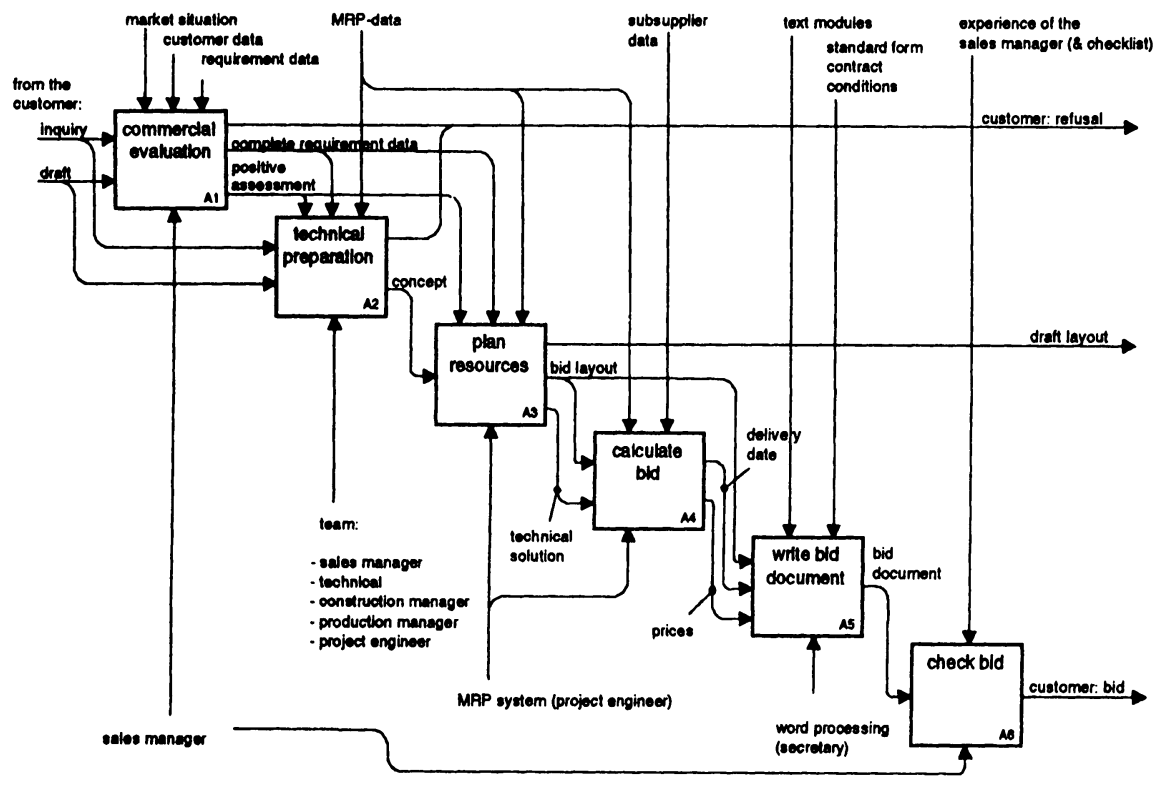

Fig. 4: Bid Preparation at Guehring Automation

A positive aspect of the bid preparation process at Guehring is the fact that consequences of a possible order can be simulated with the MRP system. A resource plan is prepared, for each bid. This minimizes the risk of not being able to keep delivery dates in case an order is placed. Currently, there is only poor support for the specification of the technical bid preparation and the document preparation. The bid layout is prepared manually and the text processor for the writing of the bid document is an isolated solution. 


\subsection{Bid Preparation at ABB Strommen}

ABB Strømmen produces railway cars and complete train sets for railway or tramway. The analysis revealed that bid preparation is a process involving many departments and resources. The types of bids vary from simple spare-part offers to complex bids for completely new design for train sets. Most of the bid preparation activities are based on manual routines, supported by a proprietary Design Support System, a production planning \& control system, spreadsheets and text processors. Problems occurring have included structuring data for reuse in further bids, cost estimation, long turnaround times and communication with subsuppliers.

The strong point of the bid preparation process at ABB Strømmen is the product model concept which was developed to ease the technical bid specification. A Design Support System, with integration to an MRP system, was implemented using this model.

\section{A REFERENCE MODEL FOR BID PREPARATION}

Based on the analysis of the "as-is" situation, both best practices as well as additional requirements regarding the "to-be" situation of bid preparation at the industrial partner's sites were collected and classified. They were sorted into six groups:
- inquiry assessment,
- $\quad$ bid project management,
- product design,
- cost estimation,
- $\quad$ product scheduling and
- bid document compilation.

Each group can be seen as a core activity of the overall bid preparation phase; together they form the top level of a bid preparation reference model (Fig. 5). It describes a framework showing the roles, activities and interdependencies of the main characters during bid preparation within the context of the whole enterprise. It could probably be valid for most companies with complex products engineered- or made-to-order.

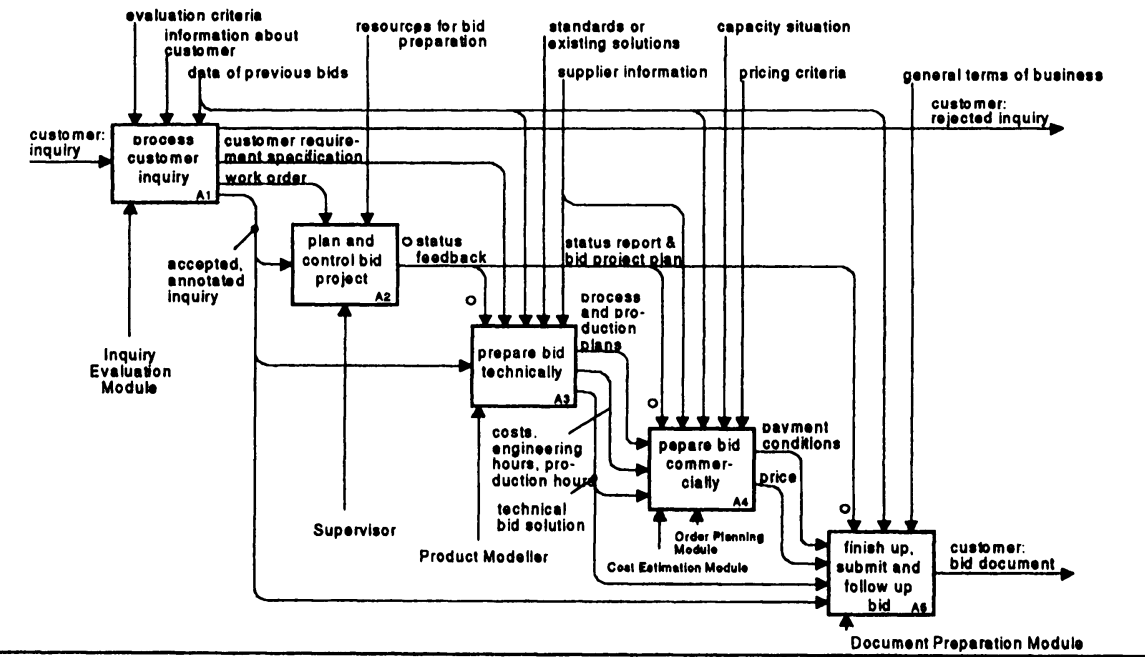

Fig. 5 A Reference Model for Bid Preparation 
Within the BIDPREP project, the reference model serves as a basis for the design of an integrated bid preparation system. The system comprises dedicated modules for the individual pre-sales activities. The modules interact via an integration mechanism, the communication bus [3]. Figure 6 describes the overall system architecture.

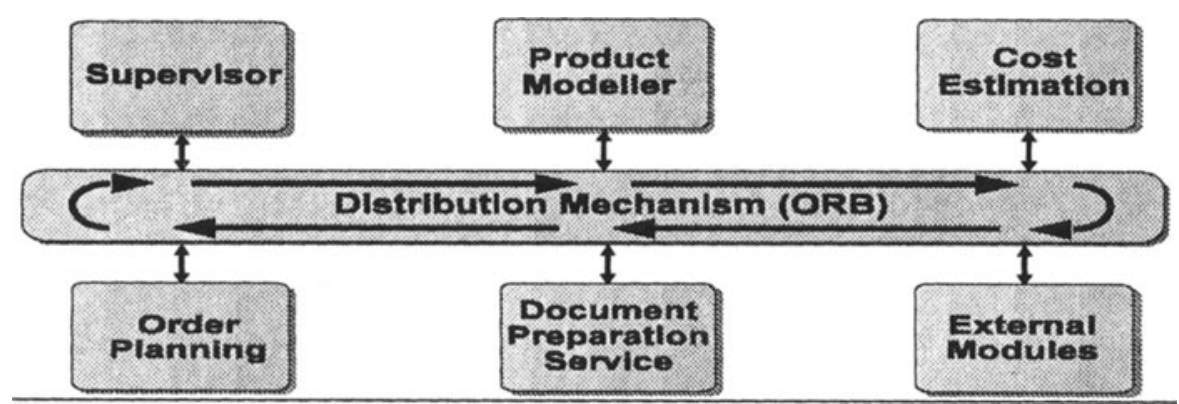

Fig. 6 The Overall Architecture of the BIDPREP System

\section{CONCLUSION}

In the BIDPREP project, benchmarking was applied in order to improve the bid preparation process by performing the following steps:

1) Definition of the objectives (what should be improved),

2) Selection of benchmarking partners (companies, research institutes),

3) Forming of benchmarking teams (national subgroups),

4) Capturing and analysis of current processes at the companies' sites,

5) Definition and implementation of improvements.

This case example proves the theory that production processes of different companies can be compared with each other even if the product and/or the branch differs. Benchmarking strategies were used to analyze the execution of the core activities at the industrial partners sites. Both bottlenecks as well as "best practices" - like the product model concept from ABB, the management concept from Krüger - formed the basis for the specification of an overall bid preparation system capable of supporting all activities related to the preparation of bids.

The prototype system will by customized to the individual needs of the involved industrial partners. Expected results comprise improved chances of winning contracts, savings in time and money, wider support of bid-related activities, quicker average response times and more precise cost calculations and correct responses to inquiries.

\section{REFERENCES}

[1] K.-D. Thoben, T. Kuhlmann, C. Lischke, R. Oehlmann: "Concurrent Engineering in der Unikatfertigung", in "CIM Management 2/1993".

[2] G. J. Colquhoun, R. W. Baines "A generic IDEF0 model of process planning" in "Int. J. Prod. Res., 1991, Vol. 29, No. 11".

[3] Object Management Group: "The Common Object Request Broker: Architecture and Specification", Object Management Group, San Diego, CA, USA, 1992. 